\title{
Analysis and improvement of the efficiency of frequency converters with pulse width modulation
}

\author{
Bogdan Vasilev \\ Department of electric power and electromechanics, Saint-Petersburg Mining University, Russian Federation
}

\begin{tabular}{l} 
Article Info \\
\hline Article history: \\
Received Jan 19, 2019 \\
Revised Mar 4, 2019 \\
Accepted Mar 12, 2019 \\
\hline
\end{tabular}

\section{Keywords:}

Electric drive

Frequency converter

Pulse-width modulation

Simulation model

Two-level autonomous inverter

\begin{abstract}
In order to identify the best control algorithm, the effects of modulation control algorithms on the energy characteristics of a two-level autonomous frequency converter inverter were studied. The research was carried out by the methods of mathematical and simulation modeling. The equa-tions of mathematical description were compiled taking into account a number of generally accepted assumptions. An equivalent circuit of a two-level autonomous inverter was created. Comparisons of pulse-width modulation algorithms with carrier signals of various shapes and frequencies were made. Three different forms of carrier signal were used: triangular, sawtooth with a falling edge and sawtooth with a leading edge. Studies were conducted at frequencies of 3,000, 6,000 and 9,000 Hz. Conclusions were made about the identity of the spectral composition of the front and rear edges of the sawtooth signal, it was also noted that with the triangular waveform, being the part of the har-monics, present in the sawtooth form is removed, so, the triangular shape provides the best result of the autonomous inverter. Also, by increasing in the carrier frequency, it was noted that pulse packets appear at different harmonic numbers, shift, and the amplitude and distortion factor decrease, that means, the best performance was obtained at the maximum frequency studied. In the study of the voltage at the output of the chokes at different frequencies of the carrier signal, it was noted that at a higher frequency, the ripple of the output voltage decreases. Throttles do not eliminate harmonics, but only reduce their amplitude. Based on the results, it was concluded that the algorithm with a triangular carrier signal and the maximum frequency provides the best harmonic composition of the output voltage of the frequency converter.
\end{abstract}

Copyright () 2019 Institute of Advanced Engineering and Science. All rights reserved.

Corresponding Author:

Bogdan Vasilev,

Department of electric power and electromechanics,

Saint-Petersburg Mining University,

2, 21st Line, St Petersburg 199106, Russia.

Email: vasilev.bu@yandex.ru

\section{INTRODUCTION}

Nowadays, in modern electric drives frequency converters are used for smooth control of electromagnetic and mechanical variables of the electric drive [1-5]. A diagram of a typical frequency converter is shown in Figure 1. A two-level autonomous inverter (AI) is installed at the output of the frequency converter [6-10]. The modulation control system is used to control a two-level AI, which is part of an electric drive control system, on the algorithms of which the energy characteristics of the frequency converter (FC) and the whole electric drive as well. The most widely used algorithms are sinusoidal PWM, which can be modified by changing the shape of the carrier signal [11-15]. The study of this topic allows us to formulate recommendations on the choice of the form and frequency of the carrier signal. 


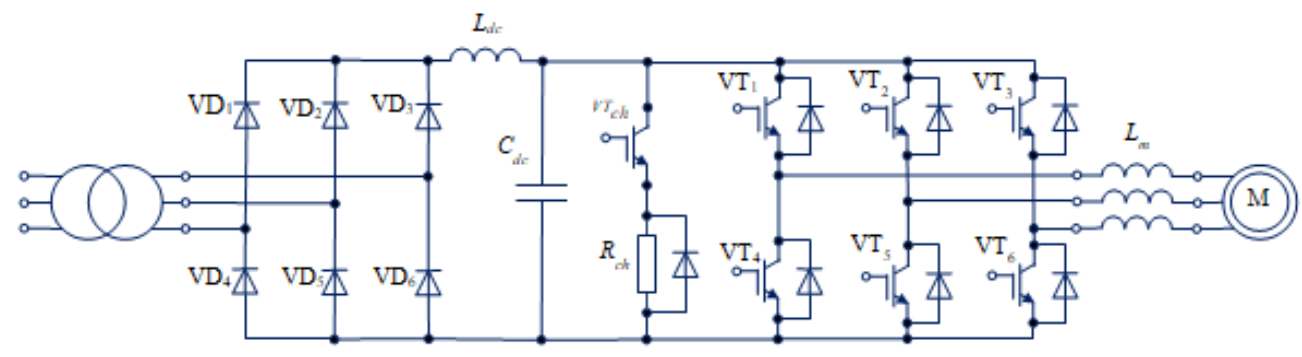

Figure 1. Diagram of a typical frequency converter

To control two-level AI transistors, the PWM system generates switching functions, which are control signals. Two signals are used to form the switching functions: controller; carrying [16-18]. The energy characteristics of an autonomous inverter depend on the form and parameters of the carrier signal, such as: voltage form; voltage spectral factor; distortion factor [19-21]. Using triangular and sawtooth signals and changing their frequency, we research by using Matlab Simulink by means of simulation and mathematical modeling.

\section{RESEARCH METHOD}

For simulating the operation of a two-level AI with the ability to research the characteristics of various control algorithms, it is necessary to solve the following tasks: to accept an assumptions; to make an equivalent circuit; to make a mathematical description of the AI; to perform an synthesis of the PWM algorithm; to create a block diagram of a mathematical description and control system; to release a simulation model using the Matlab program; to make research and analysis of energy characteristics.

In compiling the equations of the mathematical model of a two-level AI, the generally ac-cepted assumptions about the ideality of semiconductor switches are used, and the transition to an equivalent circuit is performed [22-25]. The equivalent scheme of a two-level AI is shown in Figure 2. In Figure 2 the following notations are taken: $\mathrm{K}_{1}, \mathrm{~K}_{2}, \mathrm{~K}_{3}, \mathrm{~K}_{4}, \mathrm{~K}_{5}, \mathrm{~K}_{6}$ - ideal inverter switches; $\mathrm{U}_{\mathrm{dc}}$ - equiva-lent voltage source; $\mathrm{S}_{1}, \mathrm{~S}_{2}, \mathrm{~S}_{3}, \mathrm{~S}_{4}, \mathrm{~S}_{5}, \mathrm{~S}_{6}$ - switching functions of the keys; $\mathrm{U}_{\mathrm{A}}, \mathrm{U}_{\mathrm{B}}, \mathrm{U}_{\mathrm{C}}$ - phase voltages; $\mathrm{U}_{\mathrm{AB}}, \mathrm{U}_{\mathrm{BC}}$, $\mathrm{U}_{\mathrm{CA}}$ - linear voltage; $\mathrm{Z}$ - equivalent load.

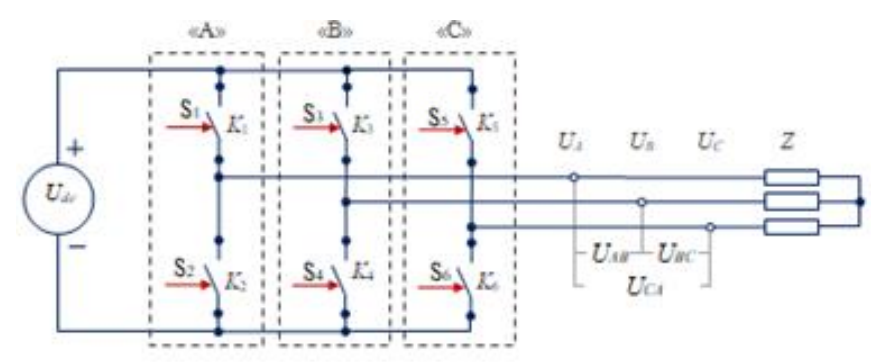

Figure 2. Equivalent circuit of two-level autonomous inverter

The mathematical model of motor chokes can be represented as follows (1):

$$
\begin{aligned}
& \frac{d U_{s A}}{d t}=\frac{R_{d r}}{L_{d r}}\left(U_{i A}-U_{s A}\right) \\
& \frac{d U_{s B}}{d t}=\frac{R_{d r}}{L_{d r}}\left(U_{i B}-U_{s B}\right) \\
& \frac{d U_{s C}}{d t}=\frac{R_{d r}}{L_{d r}}\left(U_{i C}-U_{s C}\right)
\end{aligned}
$$

where $\mathrm{R}_{\mathrm{dr}}$ and $\mathrm{L}_{\mathrm{dr}}$ - resistance and inductance of the winding of the choke. 
The phase voltage at the output of the two-level AI is as follows (2):

$$
\begin{aligned}
& U_{i A}=U_{d c}\left(+\frac{2}{3} S_{A}-\frac{1}{3} S_{B}-\frac{1}{3} S_{C}\right) \\
& U_{i B}=U_{d c}\left(-\frac{1}{3} S_{A}+\frac{2}{3} S_{B}-\frac{1}{3} S_{C}\right) \\
& U_{i C}=U_{d c}\left(-\frac{1}{3} S_{A}-\frac{1}{3} S_{B}+\frac{2}{3} S_{C}\right)
\end{aligned}
$$

where $\mathrm{U} d c$ - voltage on the capacitors of the DC link (input voltage of the inverter); $\mathrm{U}_{\mathrm{iA}}, \mathrm{U}_{\mathrm{iB}}, \mathrm{U}_{\mathrm{iC}}$ - output phase voltages (inverter output voltage)

The equations for describing racks of a two-level AI are as follows (3):

$$
\begin{aligned}
& S_{A}=1, \text { если } S_{1}=1, S_{2}=0 \\
& S_{A}=0, \text { если } S_{1}=0, S_{2}=1 \\
& S_{B}=1, \text { если } S_{3}=1, S_{4}=0 \\
& S_{B}=0, \text { если } S_{3}=0, S_{4}=1 \\
& S_{C}=1, \text { если } S_{5}=1, S_{6}=0 \\
& S_{C}=0, \text { если } S_{5}=0, S_{6}=1
\end{aligned}
$$

where $S_{A}, S_{B}, S_{C}-$ the modulation functions of the AI racks.

The rule of control of the status of racks of transistors AI (the rule of formation of the commutation function) is as follows (4):

$$
\begin{array}{ll}
\text { если } & U_{s t}^{*}>U_{s e t} \Rightarrow S_{A}=1 \\
\text { если } & U_{s A}^{*}<U_{s e t} \Rightarrow S_{A}=0 \\
\text { если } & U_{s B}^{*}>U_{s e t} \Rightarrow S_{B}=1 \\
\text { если } & U_{s B}^{*}<U_{s e t} \Rightarrow S_{B}=0 \\
\text { если } & U_{s C}^{*}>U_{s e t} \Rightarrow S_{C}=1 \\
\text { если } & U_{s C}^{*}<U_{s e t} \Rightarrow S_{C}=0
\end{array}
$$

The simulation model of two-level AI, which created in Matlab on the basis of (1)-(4), is presented in Figure 3. The two-level autonomous inverter model with the ability to research the influence of the following factors, such as the frequency and form of a non-existent signal, various algorithms and analysis of the characteristics of the inverter includes: the PWM, the inverter and the chokes.

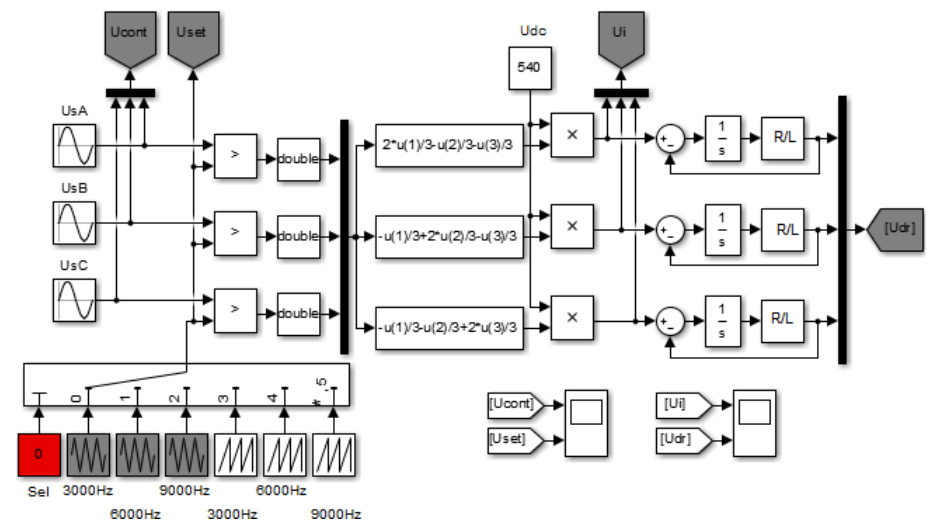

Figure 3. Effects of selecting different switching under dynamic condition 


\section{RESULTS AND ANALYSIS}

Three types of signals can be used to control two-level AI: triangular as shown in Figure 4 (a), sawtooth with front edge as shown in Figure 4 (b), sawtooth with a falling edge as shown in Figure 4 (c). In Figure 5 shows waveform oscillograms of the output voltage of an autonomous inverter and motor chokes at a frequency of the carrier signal of $3000 \mathrm{~Hz}$.

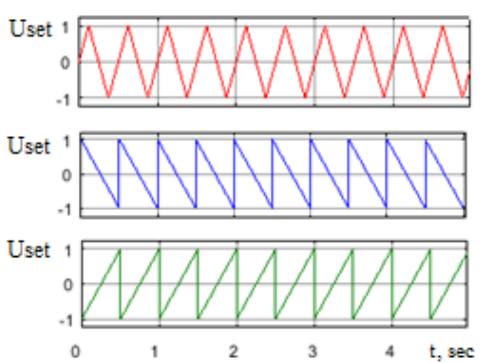

Figure 4. Effects of selecting different switching under dynamic condition

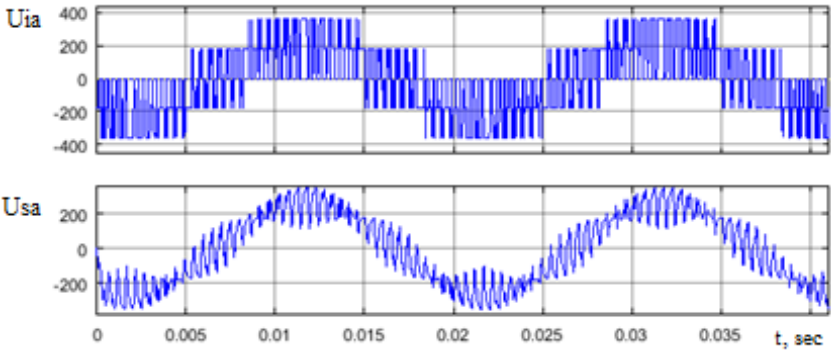

Figure 5. Effects of selecting different switching under dynamic condition

In the study of the control algorithms of the inverter consider the impact of:

- carrier waveform on the characteristics of the AI;

- frequency carrier signal on the characteristics of the AI;

- chokes on the harmonic components of the voltage AI.

In the simulation modeling, the oscillograms of the voltage at the output of the autonomous inverter and motor chokes are built, and their spectral composition is also investigated.

\subsection{Influence of the shape of the carrier signal on the characteristics of the frequency converter}

In Figure 6 shows the spectral composition of the output voltage at different waveforms: triangular as shown in Figure 6 (a), sawtooth with a falling edge as shown in Figure 6 (b) and sawtooth with a leading edge as shown in Figure 6 (c). Studies were conducted at a frequency of $3000 \mathrm{~Hz}$.

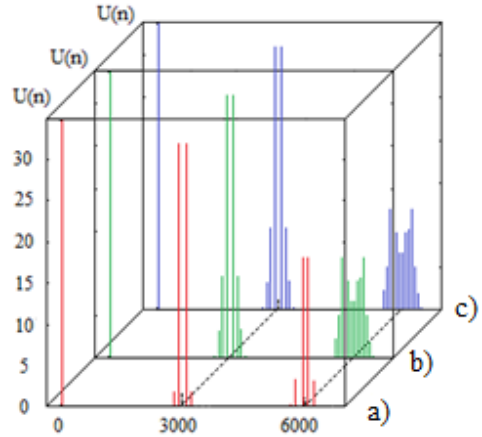

Figure 6. The influence of the form of the carrier signal on the harmonic composition of the output voltage AI

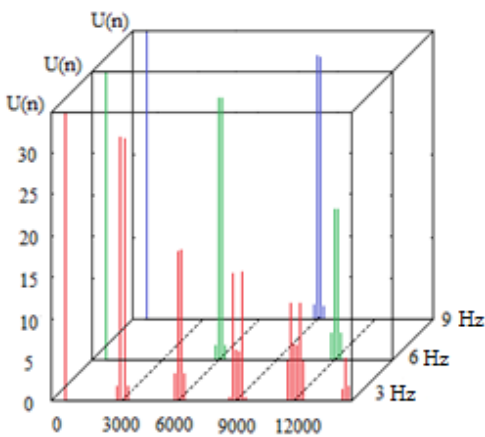

Figure 7. The effect of the carrier frequency on the harmonic composition of the output voltage AI

On the basis of the results, we conclude that the spectral composition of the front coincides with the spectral composition of the rear front. With a sawtooth form, the density of the spectral composition is higher than with a triangular one.

\subsection{The effect of the carrier frequency on the characteristics of the converter frequency}

Since in the first part of the study it was found that the best harmonic composition of the output voltage $\mathrm{AI}$ is provided with a triangular form of the carrier signal, the effect of the frequency of the carrier signal will be considered only with this form. In Figure 7 shows the spectral composition of the output voltage with a triangular signal at different frequencies. 
Based on the results obtained, it can be concluded that the best regulation is provided at a frequency of $9 \mathrm{KHz}$. Pulse packets are formed at a carrier signal frequency and, with increasing frequency, are shifted to the high-frequency region.

\subsection{Effect of chokes on the harmonic components of the voltage}

In Figure 8 shows oscillograms of voltage at the output of motor chokes at different frequencies of the carrier signal. In Figure 9 the dependence of the nonlinear distortion coefficient (THD) on the ratio of inductance to resistance of chokes

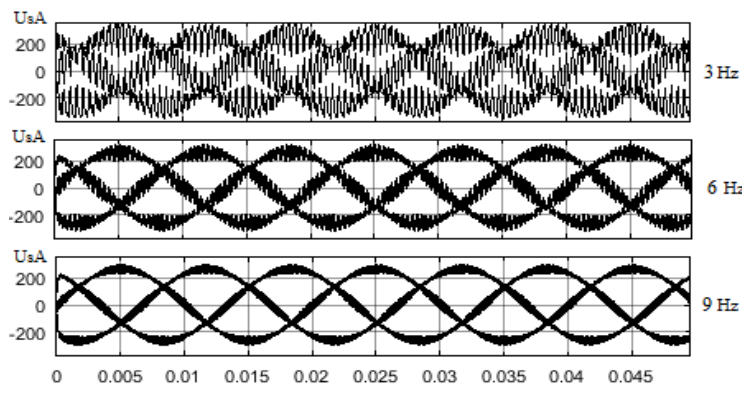

Figure 8. Voltage at the output of chokes depending on the different frequency of the carrier signal

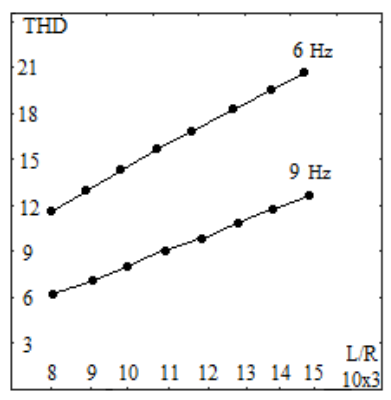

Figure 9. The dependence of the nonlinear distortion coefficient (THD) on the ratio of inductance to resistance of chokes

Based on the results, it can be concluded that the best regulation is provided at a frequency of $9 \mathrm{KHz}$. As the frequency of the carrier signal increases, the number of harmonic components remains the same, only their amplitude decreases.

Power quality analysis is presented in Tables 1-4 (triangular carrier (T); sawtooth with front edge (FRE); sawtooth with a falling edge (FAE)).

Table 1 . The value of the voltage distortion coefficient at the output of the autonomous inverter

\begin{tabular}{lllllllll}
\hline $\mathrm{R}_{\mathrm{dr}} / \mathrm{L}_{\mathrm{dr}}$ & 8000 & 9000 & 10000 & 11000 & 12000 & 13000 & 14000 & 15000 \\
$\mathrm{THDi}$ & 68,9 & 68,9 & 68,9 & 68,9 & 68,9 & 68,9 & 68,9 & 68,9 \\
THDdr $(9000 \mathrm{~Hz})$ & 6,1 & 6,8 & 7,6 & 8,3 & 9 & 9,8 & 10,5 & 11,2 \\
THDdr $(6000 \mathrm{~Hz})$ & 11,9 & 13,4 & 14,7 & 16 & 17 & 18,6 & 19,8 & 21 \\
\hline
\end{tabular}

Table 2. The amplitude of the harmonic components of the autonomous output voltage the inverter at a carrier signal frequency of $3000 \mathrm{~Hz}$

\begin{tabular}{|c|c|c|c|c|c|c|c|c|c|c|c|c|}
\hline \multirow[t]{2}{*}{$\mathrm{f}$} & \multicolumn{4}{|c|}{$\mathrm{f}_{1}=3000 \mathrm{~Hz}$} & \multicolumn{4}{|c|}{$\mathrm{f}_{3}=6000 \mathrm{~Hz}$} & \multicolumn{4}{|c|}{$\mathrm{f}_{3}=9000 \mathrm{~Hz}$} \\
\hline & $\mathrm{n}$ & $\mathrm{T}$ & FRE & FAE & $\mathrm{n}$ & $\mathrm{T}$ & FRE & FAE & $\mathrm{n}$ & $\mathrm{T}$ & FRE & FAE \\
\hline 0 & 60 & - & - & - & 120 & - & - & - & 180 & - & - & - \\
\hline \pm 50 & $59 / 61$ & - & 18 & 18 & $119 / 121$ & 18 & 7 & 7 & $179 / 181$ & - & 4 & 4 \\
\hline \pm 100 & $58 / 62$ & 32 & 31 & 31 & $118 / 122$ & - & 10 & 10 & $178 / 182$ & 6 & 5 & 5 \\
\hline \pm 150 & $57 / 63$ & - & - & - & $117 / 123$ & - & - & - & $177 / 183$ & - & - & - \\
\hline \pm 200 & $56 / 64$ & 2 & 10 & 10 & $116 / 124$ & - & 10 & 10 & $176 / 184$ & 15 & 6 & 6 \\
\hline \pm 250 & $55 / 65$ & - & 3 & 3 & $115 / 125$ & 3 & 12 & 12 & $175 / 185$ & - & 3 & 3 \\
\hline \pm 300 & $54 / 66$ & - & - & - & $114 / 126$ & - & - & - & $174 / 186$ & - & - & - \\
\hline
\end{tabular}

Table 3. The amplitude of the harmonic components of

the autonomous output voltage inverter with a carrier signal frequency of $6000 \mathrm{~Hz}$

\begin{tabular}{|c|c|c|c|c|c|c|c|c|c|c|c|c|}
\hline \multirow[t]{2}{*}{$\mathrm{f}$} & \multicolumn{4}{|c|}{$\mathrm{f}_{1}=3000 \mathrm{~Hz}$} & \multicolumn{4}{|c|}{$\mathrm{f}_{3}=6000 \mathrm{~Hz}$} & \multicolumn{4}{|c|}{$\mathrm{f}_{3}=9000 \mathrm{~Hz}$} \\
\hline & $\mathrm{n}$ & $\mathrm{T}$ & FRE & FAE & $\mathrm{n}$ & $\mathrm{T}$ & FRE & FAE & $\mathrm{n}$ & $\mathrm{T}$ & FRE & FAE \\
\hline 0 & 60 & - & - & - & 120 & - & - & - & 180 & - & - & - \\
\hline \pm 50 & $59 / 61$ & - & - & - & $119 / 121$ & - & 18 & 18 & $179 / 181$ & - & - & - \\
\hline \pm 100 & $58 / 62$ & - & - & - & $118 / 122$ & 32 & 31 & 31 & $178 / 182$ & - & - & - \\
\hline \pm 150 & $57 / 63$ & - & - & - & $117 / 123$ & - & - & - & $177 / 183$ & - & - & - \\
\hline \pm 200 & $56 / 64$ & - & - & - & $116 / 124$ & 2 & 10 & 10 & $176 / 184$ & - & - & - \\
\hline \pm 250 & $55 / 65$ & - & - & - & $115 / 125$ & - & 3 & 3 & $175 / 185$ & - & - & - \\
\hline \pm 300 & $54 / 66$ & - & - & - & $114 / 126$ & - & - & - & $174 / 186$ & - & - & - \\
\hline
\end{tabular}


Table 4. The amplitude of the harmonic components of the autonomous output voltage inverter with a carrier frequency of $9000 \mathrm{~Hz}$

\begin{tabular}{|c|c|c|c|c|c|c|c|c|c|c|c|c|}
\hline \multirow[t]{2}{*}{$\mathrm{f}$} & \multicolumn{4}{|c|}{$\mathrm{f}_{1}=3000 \mathrm{~Hz}$} & \multicolumn{4}{|c|}{$\mathrm{f}_{3}=6000 \mathrm{~Hz}$} & \multicolumn{4}{|c|}{$\mathrm{f}_{3}=9000 \mathrm{~Hz}$} \\
\hline & $\mathrm{n}$ & $\mathrm{T}$ & FRE & FAE & $\mathrm{n}$ & $\mathrm{T}$ & FRE & FAE & $\mathrm{n}$ & $\mathrm{T}$ & FRE & FAE \\
\hline 0 & 60 & - & - & - & 120 & - & - & - & 180 & - & - & - \\
\hline \pm 50 & $59 / 61$ & - & - & - & $119 / 121$ & - & - & - & $179 / 181$ & - & 18 & 18 \\
\hline \pm 100 & $58 / 62$ & - & - & - & $118 / 122$ & - & - & - & $178 / 182$ & 32 & 31 & 31 \\
\hline \pm 150 & $57 / 63$ & - & - & - & $117 / 123$ & - & - & - & $177 / 183$ & - & - & - \\
\hline \pm 200 & $56 / 64$ & - & - & - & $116 / 124$ & - & - & - & $176 / 184$ & 2 & 10 & 10 \\
\hline \pm 250 & $55 / 65$ & - & - & - & $115 / 125$ & - & - & - & $175 / 185$ & - & 3 & 3 \\
\hline \pm 300 & $54 / 66$ & - & - & - & $114 / 126$ & - & - & - & $174 / 186$ & - & - & - \\
\hline
\end{tabular}

\section{CONCLUSION}

The autonomous frequency converter can draw the following conclusions: (1) Depending on the modification of the algorithm of pulse-width control of the output voltage in accordance with the task; (2) The shape of the carrier signal affects the harmonic state of the output voltage of an autonomous inverter; (3) Carrying a sawtooth signal, regardless of the front in the equally harmonious composition of the output voltage; (4) By using the pulse-width modulation of a triangular carrier signal, the harmonic composition of the output voltage is more favorable than when using a sawtooth signal; (5) The frequency of the carrier signal determines the switching frequency of an autonomous inverter, which in turn determines the position of the stationary pulse packets; (6) The packages of voltage pulses are formed at a frequency that is a multiple of the frequency of the carrier signal; (7) By increasing the frequency of the pulse packets are shifted to high frequencies; (8) To harmonize the shape of the output voltage of the autonomous inverter and load, it is advisable and efficient to use motor chokes; (9) Using the chokes it leads to a decrease in the amplitude of the harmonic components of the output voltage while maintaining the number of harmonic components in the spectrum.

Thus, the choice of methods for modifying the pulse-width control algorithms should be carried out comprehensively. When choosing methods it is necessary to take into account: carrier waveform; frequency of the carrier signal; choke parameters. All these parameters have a significant impact on the energy characteristics of frequency converters and their compatibility with the load.

In the practical implementation of the control system, the weight and dimensions of chokes and the electric drive as a whole, the efficiency of an autonomous inverter motor and the inverter as a whole, insulation requirements for the drive motor windings, their aging speed and service life de-pend on the correctness of the choice.

\section{REFERENCES}

[1] X. Xu, L. Fang, X. Xu and X. Lu, "Control strategy of photovoltaic generation inverter grid-connected operating and harmonic elimination hybrid system," 2017 2nd International Conference on Power and Renewable Energy (ICPRE), Chengdu, pp. 886-890, 2017.

[2] W. Guo, T. Mingxing and R. Enen, "Structure design and its parameter optimization of output filter in current balance compensation inverter for electrified railway," The 2nd International Symposium on Power Electronics for Distributed Generation Systems, Hefei, pp. 791-795, 2010.

[3] H. M. Ahn, W. Sung, M. Kim, B. K. Lee, S. Ryu and C. Lim, "Control method of input-parallel and output-series connected inverters for plasma generator," 2018 IEEE Applied Power Electronics Conference and Exposition (APEC), San Antonio, TX, pp. 3563-3568, 2018.

[4] M. Song, C. Gao, J. Yang and H. Yan, "Energy storage modeling of inverter air conditioning for output optimizing of wind generation in the electricity market," in CSEE Journal of Power and Energy Systems, vol. 4, no. 3, pp. 305-315, September 2018.

[5] Xin Li and S. S. Williamson, "Efficiency analysis of hybrid electric vehicle (HEV) traction motor-inverter drive for varied driving load demands," 2008 Twenty-Third Annual IEEE Applied Power Electronics Conference and Exposition, Austin, TX, pp. 280-285, 2008.

[6] V.V. Alekseev, V. I. Vershinin and B.Yu. Vasil'ev, "Definition of parameters of vectors of magnetic flux in electric drives with the vector control," Zapiski Gornogo Instituta/Journal of Mining Institute, 196, pp. 222-225, 2012.

[7] A. Anuchin, D. Shpak, A. Zharkov, V. Ostrirov and Y. Vagapov, "A method of determining the maximum performance torque-speed characteristic for an induction motor drive over its entire speed range," 2017 IEEE 58th International Scientific Conference on Power and Electrical Engineering of Riga Technical University (RTUCON), Riga, pp. 1-5, 2017.

[8] G. Yang, M. Lin, G. Tan and H. Li, "Direct Input Power Control for Drive System of Single-Phase to Three-Phase Power Converter Without Electrolytic Capacitor," 2018 21st International Conference on Electrical Machines and Systems (ICEMS), Jeju, pp. 1503-1507, 2018.

[9] Zhongyuan Zhao, Zhengyu Lu, Gaoxian Jin, Wanmen Fei and Linghui Xia, "Development of gate-driving system of thyristor valve with multiple isolated outputs used in new-type solid-state short-circuit fault current limiter in 
electric power system," 2004 IEEE 35th Annual Power Electronics Specialists Conference (IEEE Cat. No.04CH37551), Aachen, Germany, pp. 3233-3236, 2004.

[10] B. Yu.Vasil'ev, V. A. Shpenst, O. V. Kalashnikov, and G. N. Ul'yanov, "Providing energy decoupling of electric drive and electric grids for industrial electrical installations," Zapiski Gornogo Instituta/Journal of Mining Institute, 229, pp. 41-49, 2018.

[11] V. Ansal, P. Parthiban and K. Ravikumar, "Performance study of high frequency link AC-AC converter," 2014 International Conference on Advances in Energy Conversion Technologies (ICAECT), Manipal, pp. 164-168, 2014.

[12] P. Szczesniak, "Basic Properties Comparative Study of Matrix-Reactance Frequency Converter Based on BuckBoost Topology with Venturini Control Strategies," 2007 Compatibility in Power Electronics, Gdansk, pp. 1-7, 2007.

[13] T. Shimizu, K. Kunomura, M. Kai, H. Miyajima and T. Matsui, "Study for further introduction of the Electronic Frequency converters to the Tokaido Shinkansen," 2018 International Power Electronics Conference (IPEC-Niigata 2018 -ECCE Asia), Niigata, pp. 1803-1809, 2018.

[14] Toni, F. D. Wijaya and E. Firmansyah, "Full-bridge inverter phase-shifted PWM (FBPS-PWM) zero voltage switching (ZVS) and high frequency transformer as part of DC-DC converter 311/100V 300W," 2014 International Conference on Electrical Engineering and Computer Science (ICEECS), Kuta, pp. 298-301, 2014.

[15] H. Zuo, J. Wang, J. Zhao and L. Zhou, "Simulation Study on Commutation Leading Angle Control of Static Frequency Converter for the Startup of Large-scale Synchronous Condenser," 2018 IEEE Student Conference on Electric Machines and Systems, HuZhou, China, pp. 1-4, 2018.

[16] Jin-Hyung Yoo, June-Woo Jo and Tae-Uk Jung, "A study on design and optimization procedure of high frequency transformer for module-integrated converter," 2014 16th European Conference on Power Electronics and Applications, Lappeenranta, pp. 1-8, 2014.

[17] A. L. A. da Fonseca, J. A. Lambert, R. V. A. Monteiro, A. B. de Vasconcellos and B. C. Carvalho, "Behavioral and statistical analysis of total harmonic distortion input frequency converter of a triggering an industrial fan: A case study," 2014 16th International Conference on Harmonics and Quality of Power (ICHQP), Bucharest, pp. 152-156, 2014.

[18] G. Gök, I. Alişar and D. Gökcen, "Structural Comparison of Wide Band-Gap Semiconductors with Silicon Semiconductors and Performance Oriented Comparison for a High Switching Frequency Flyback Converter," 2018 2nd International Symposium on Multidisciplinary Studies and Innovative Technologies (ISMSIT), Ankara, pp. 1-5, 2018.

[19] G. R. Kamath, "Simulation study of a simple flux saturation controller for high-frequency transformer link fullbridge DC-DC converters," 2012 IEEE International Conference on Power Electronics, Drives and Energy Systems (PEDES), Bengaluru, pp. 1-5, 2012.

[20] Chenyou Li, Guang Zhang and Z. Yan, "Study on four PWM modulation strategies of the high frequency link matrix converter with BLDCM load," 2016 IEEE 8th International Power Electronics and Motion Control Conference (IPEMC-ECCE Asia), Hefei, pp. 1854-1857, 2016.

[21] Atsushi Hirota, Satoshi Nagai, Bishwajit Saha and Mutsuo Nakaoka, "Fundamental study of a simple control ac-ac converter introducing delta-sigma modulation approach," 2008 IEEE International Conference on Industrial Technology, Chengdu, pp. 1-5, 2008..

[22] T. Shimada and K. Taniguchi, "IGBT/MOSFET hybrid bridge with phase shift and frequency modulation control for a bi-directional series resonant converter," 2017 19th European Conference on Power Electronics and Applications (EPE'17 ECCE Europe), Warsaw, pp. P.1-P.7, 2017.

[23] R. Barrera-Cardenas and M. Molinas, "Comparative study of the converter efficiency and power density in offshore wind energy conversion system with single-phase transformer," International Symposium on Power Electronics Power Electronics, Electrical Drives, Automation and Motion, Sorrento, 2012, pp. 1085-1090.

[24] T. Ibuchi and T. Funaki, "A study on parasitic inductance reduction design in GaN-based power converter for highfrequency switching operation," 2017 International Symposium on Electromagnetic Compatibility - EMC EUROPE, Angers, 2017, pp. 1-5.

[25] W. Fa-Qiang, M. Xi-Kui and Y. Ye, "Low frequency oscillation in the PI type of average current controlled Boost converter," 2011 International Conference on Electronics, Communications and Control (ICECC), Ningbo, 2011, pp. 3792-3795.

\section{BIOGRAPHY OF AUTHOR}

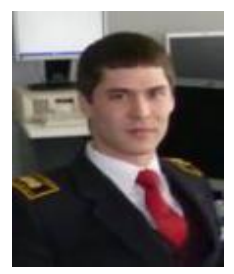

Graduated from Uchtincskiy technical university in 2010. Received P.H.D. degree in National Mineral Resources University in 2013. He is assistant professor in electrical energy and electromechanics department since 2013. His research interest includes electromagnetic compatibility providing, electrotechnical systems for energy industry 